\title{
Effectiveness of functioning of arc steel furnaces under changes of voltages in arc discharges
}

\author{
Bikeev R.A. \\ Dept. of Electrotechnology \\ Novosibirsk State Technical University \\ Novosibirsk, Russia \\ bikeev@ngs.ru \\ Korovin V.E. \\ Dept. of Electrotechnology \\ Novosibirsk State Technical University \\ Novosibirsk, Russia \\ elterm@ngs.ru
}

\author{
Cherednichenko V.S. \\ Dept. of Electrotechnology \\ Novosibirsk State Technical University \\ Novosibirsk, Russia \\ gk@therm.ru \\ Rakina M.D. \\ Dept. of Electrotechnology \\ Novosibirsk State Technical University \\ Novosibirsk, Russia \\ elterm@ngs.ru
}

\author{
Serikov V.A. \\ Dept. of Electrotechnology \\ Novosibirsk State Technical University \\ Novosibirsk, Russia \\ victorserikov@yandex.ru
}

\begin{abstract}
On the basis of a previously developed mathematical model of electromagnetic power transfer between phases, an investigation of effectiveness of the functioning of the arc steel furnace EAF-100 with coplanar construction of the secondary current lead in the modes of "short", "medium" and "long" arc discharges was carried out. It was ascertained that the electromechanical processes in EAF are defined not only by the gradients of potential in arc discharges, but also by the electromagnetic processes of interaction between phases, which lead to rearrangement of integral power, generated by arc discharges. Recommendation on the employment of a reactor with separately controlled phases for the operation of the furnace in the long arc mode was formulated.
\end{abstract}

Keywords-arc steel furnace, power transfer between phases, "short" and "long" arc discharges, optimization of power.

\section{INTRODUCTION}

Modern arc steel furnaces of alternating current (EAF) are operated with increased secondary voltages of the furnace transformer and application of the power supply system for additional reactors on the primary side of the transformer. Furnaces with such power supply systems enable one to carry out melting with long arcs without any decline in power by increasing secondary voltage. Application of such modes of functioning with all other conditions remaining constant increases stability of the burning of arcs and diminishes the risk of short circuits. These properties of long arc modes have been detected through experiments, but the physical processes behind them still remain unknown.
The short arc mode reveals more apparently the cutting properties of arc discharges and their diminished stability which comes from decreased voltages in the burning of consecutive arcs [1, 2]. The formation of near-electrode processes and borderline thermal layers on the scrap is greatly influenced by the vibrational processes which emerge from the interaction of acoustic energy with hard metal [3]. In such conditions, arc discharges cause mechanical destruction of metal, and arcs tend to cut and break the scrap rather than heat the metal [4-13].

Near-sonic speeds of plasmic axial jets of the arc discharges provide turbulent flow of steam currents in gas environment, which influences probable values of voltage gradient in the arc discharges and dispersion of phase currents [14]. Six-fold alteration of the direction of the currents in arcs of each electrode during one period of alternating current in three-phase circuit of the EAF produces substantial influence on the modes of burning arc discharges.

Experimental studies conducted on functioning electrical furnaces have shown that an increase in the amplitude value of sinusoidal phase voltage on the secondary side of the transformer leads to additional stabilization of arc discharges and expansion of the range of stable arc burning parameters. However, these changes lead to strengthening of influence of effects of power transfer between phases on the modes of furnace operation.

The developed mathematical model of electric modes of operation of the EAF with consideration for electromagnetic 
interaction of phases on all segments of current lead, including arc discharges, has enabled an investigation of effectiveness of using short and long arcs in the period of melting with application of previously acquired results to be carried out. The following investigations show a possibility of researching the problems outlined in the task statement of investigating the electrical modes of operating an EAF.

\section{ANALYSIS OF THE OPERATION MODES OF EAF}

The variety of factors involved in the interactions of apparent power of the furnace $\mathrm{S}$, active $\mathrm{P}$ and reactive $\mathrm{Q}$ components of energy with the secondary voltage of the transformer $U_{2}$, the dynamic resistance $R_{\text {dyn }}$ and reactance $X_{\text {dyn }}$ of the furnace's phases substantially inhibits the choice of optimal modes of operating the EAF. The employment of traditional functional characteristics and dependences of the wear index of the lining on the current, while exploiting the furnace in automatic operation modes, ensures its functioning, but does not give a definite answer to the question of optimal values of active work power of the furnace $[15,16]$.

It is shown that oscillation of functional parameters of EAF restricts the introduction of energy in the working space of the furnace. Statistical processing of a large quantity of melting cycles in EAF-100 at the same stages of functioning of the furnace has enabled one to determine a field of probable values of active power introduced into the working space of the furnace. Fig. 1 presents the dependence of experimentally determined points of active power on the phase currents along with the calculated electrical characteristic figured out by using traditional calculation methods. As seen from the figure, the measured parameters are constituted around the calculated dependence a field of exploitation values of phase power, which characterizes the oscillation of electric parameters, including that which occurs due to power transfer between the phases.

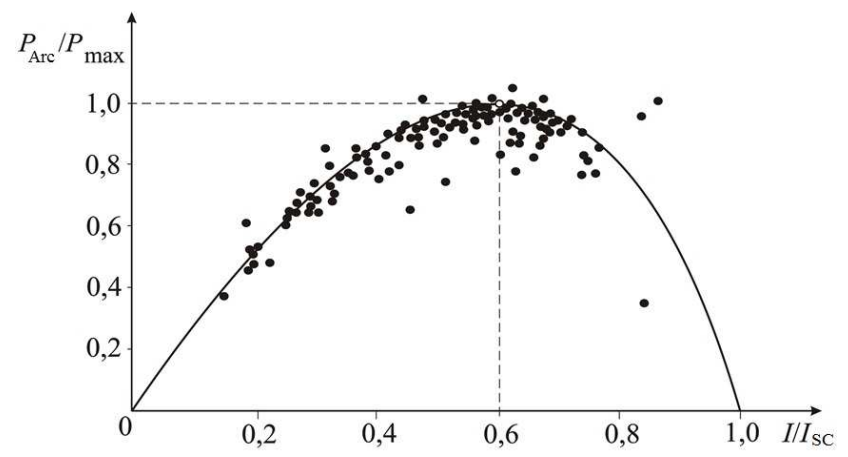

Fig. 1. Electric characteristic of phase of industrial furnace.

The physical nature of the oscillations of currents and voltages in the three-phase circuit of EAF, containing arc discharges, depends on a variety of factors and covers the range of perceptible frequencies from 0 to $400-600 \mathrm{~Hz}$. It is not possible to identify the disturbances caused by the arcs by means of measuring the phase to phase voltages in the terminals of the transformer or the currents in phases. On the basis of Kirchhoff's first law, applicable for instantaneous currents: $i_{A}+i_{B}+i_{C}=0$, oscillations of voltage of one arc and, therefore, of the current, cause changes of currents in all phases, and the electromagnetic connection of phases in current leads expands the range of frequencies and variations of oscillation amplitudes of currents and voltages.

For carrying out numerical experiments, the following conditions are assumed in order to increase uniqueness of the obtained results: the electrical furnace EAF-100 does not have any reactor on the high voltage side of the transformer in its electrical circuit; the assumed frequency is $\mathrm{f}=50 \mathrm{~Hz}$ (the existence of harmonics lower or higher than the industrial frequency is not taken into account); the object of investigation are the processes of electromagnetic energy transfer between the phases in three-phase power system of the furnace in the modes of short and long arcs.

As an object of the numerical experiment in the investigation of the electromagnetic interactions, a variant of the furnace EAF-100 with current-carrying arms and coplanar phase construction was chosen. The electrical furnace has the necessary quantity of secondary voltage steps. With such construction of the current lead of the furnace, the dynamic interactions in the power system of the EAF are seen with maximum clarity.

Certified characteristics of the furnace are accepted as starting parameters: proper inductances of secondary current lead phases - $\mathrm{L}_{\mathrm{A}}=14,8995 \mu \mathrm{H}, \quad \mathrm{L}_{\mathrm{B}}=13,998 \mu \mathrm{H}$, $\mathrm{L}_{\mathrm{C}}=14,8995 \mu \mathrm{H}$; mutual inductances of secondary current lead phases for basic geometric layout of current leads (column height of all phases corresponds to a half of electrodes' path and amounts to $1800 \mathrm{~mm}$, the fixed flexible cables are positioned symmetrically, vertically) - $\mathrm{M}_{\mathrm{AB}}=6,3093 \mu \mathrm{H}$, $\mathrm{M}_{\mathrm{BC}}=6,3076 \mu \mathrm{H}, \mathrm{M}_{\mathrm{CA}}=5,7577 \mu \mathrm{H}$. Basic proper active phase resistances of secondary current lead, taking into account the pure resistances of transformer phases, are assumed to be $\mathrm{R}_{\mathrm{A}}=\mathrm{R}_{\mathrm{B}}=\mathrm{R}_{\mathrm{C}}=0,45 \mathrm{~m} \Omega$; linear voltage of the furnace's transformer in the highest step $\mathrm{E}_{\mathrm{l}}=761 \mathrm{~V}$; inductive resistance of phases of the transformer in the highest degree of voltage $\mathrm{X}_{\mathrm{tr}}=0,45 \mathrm{~m} \Omega$. As the basic values for the analysis of variation of total inductive phase resistances of secondary current lead, the inductive resistances, calculated on the basis of basic proper inductances of phases - $\mathrm{X}_{\mathrm{A}}=4,6808 \mathrm{~m} \Omega$, $\mathrm{X}_{\mathrm{B}}=4,3976 \mathrm{~m} \Omega, \mathrm{X}_{\mathrm{C}}=4,6808 \mathrm{~m} \Omega$ - are assumed.

The investigation of functioning of the EAF under short and long arc modes was conducted in non-symmetrical modes. Dissymmetry in a three-phase EAF is most often observed when voltage in the arc discharge in one of the phases fluctuates between zero (which corresponds to short circuit in this particular phase) and a value close to phase voltage of the transformer (ark break). In the experiment, it is assumed that such change of the mode occurs in phase $\mathrm{C}$, and voltage in arc $U_{\mathrm{a} C}$ may vary from 0 to $580 \mathrm{~V}$. Modes of phases A and $\mathrm{B}$ are assumed to be equal and constant for three arc voltages: $400 \mathrm{~V}$ - long arc, $300 \mathrm{~V}$ - medium arc, $200 \mathrm{~V}$ - short arc. Order of phases: A, B, C. phases $\mathrm{A}$ and $\mathrm{C}$ are positioned symmetrically on either side of phase $B$. Phase $C$ goes ahead of phase $A$; phase B lags behind it. 


\section{DYNAMIC CHARACTERISTICS OF FUNCTIONING OF EAF DURING VARIATION OF VOLTAGES IN ARC DISCHARGES}

The determined connection of the power transfer between phases with development of current oscillations in phases and pulsation of voltages in arc discharges defines the reduction of effective active energy introduced into the working
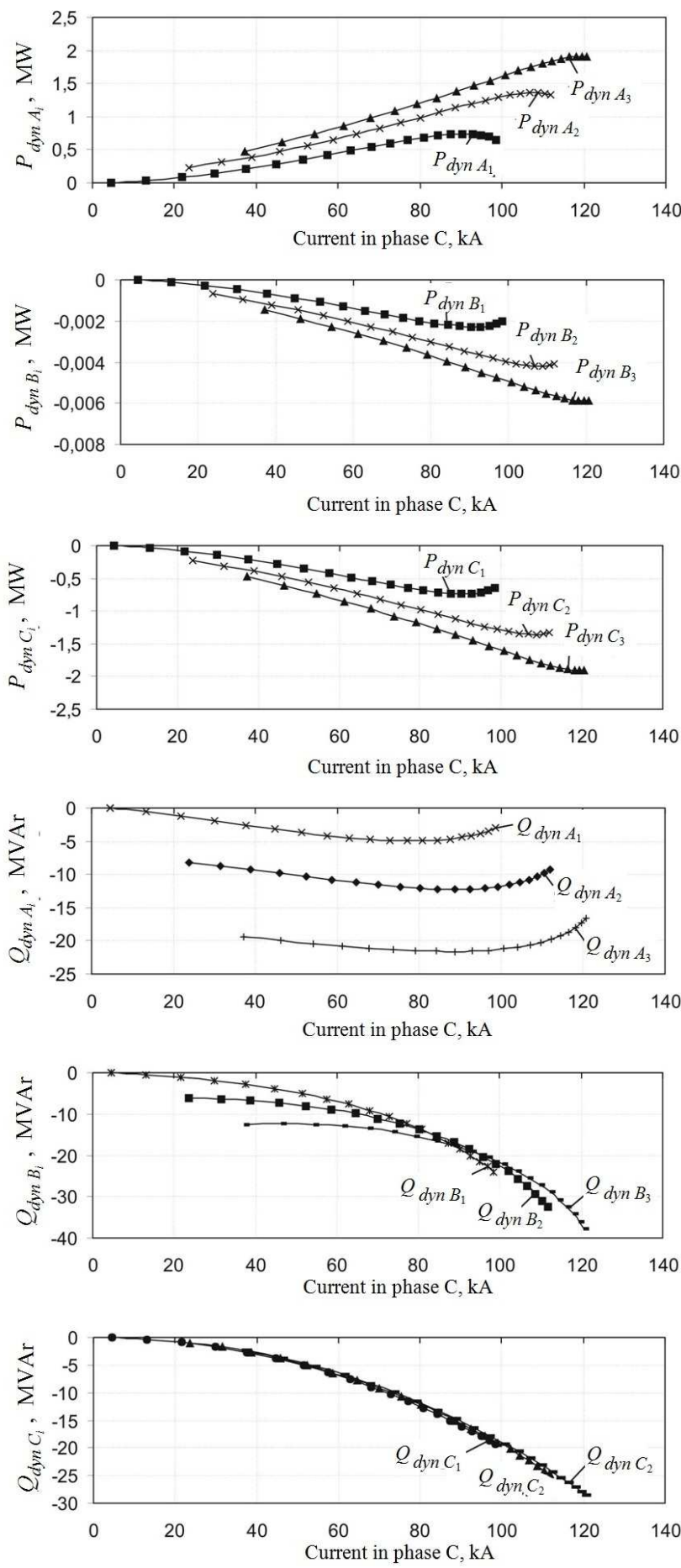

Fig. 2. Dynamic components of active and reactive powers in phases A, B, and $\mathrm{C}$ during changes of current in phase $\mathrm{C}$ with basic values of mutual inductances of phases space of the furnace (fig.1). During the exploitation of the furnace, oscillation of parameters is observed in all stages of melting, including modes of arc burning in foaming slag. Processes of electromagnetic energy transfer along the whole length of the secondary current lead intensify even the insignificant changes in currents, occurring due to movement of electrodes or interaction of arcs with the surrounding space inside the furnace. It can only be determined through numerical experiments whether or not these current variations may be ignored during the investigation.

Reliability of the employment of the mathematical model of electromagnetic transfer between phases is confirmed by experimental characteristics determined for various phases for low, medium and high currents in phases. Therefore ignoring the possible variations of current lead resistances due to swinging of flexible cables, ill-timed slipping of electrodes and changes in inductive resistances due to vertical movements of electrodes will not lead to diminished accuracy of the obtained results.

Dynamic components of active and reactive powers in phases A, B, C, existing in the three-phase circuit of EAF due to power transfer between phases, are presented in fig. 2: $1-$ long arc, 2- medium arc, 3 - short arc.

Change of voltages in arc discharges significantly alters the power transfer between phases due to the changes of pure resistances in arc discharges. The greatest deviations from the static electrical mode are observed under short arcs. If the current is raised in phase $C$, an increase in active power from 0 to $2 \mathrm{MW}$ is observed in phase $\mathrm{A}$, the power in phase $\mathrm{B}$ decreases insignificantly by $0.006 \mathrm{MW}$, and in phase $\mathrm{C}$ a substantial decrease in active power to $2 \mathrm{MW}$ is observed.

For long arc mode, the absolute values of dynamic components of active powers in phases are substantially lower. In phase $\mathrm{A}$, an increase in power to $0.6 \mathrm{MW}$ occurs, which is 3.3 times lower than the values for short arc. In phase B power decreases to $0.0023 \mathrm{MW}$, and in phase $\mathrm{C}$ - to $0.75 \mathrm{MW}$, which is 2.66-time lower than short arc values.

Dynamic components of reactive power in phases have negative values. The differences of these characteristics for short and long arc modes become most apparent in phase A, in which an increase in active power occurs. Dynamic reactive component of power for short arcs $(\approx 22 \mathrm{MVAr})$ differs from that of long arc mode $(\approx 4,9$ MVAr) 4.5 times. Substantial differences in rearrangement of active and reactive energy in short and long arc modes are explained by the fact of the intensity of electromechanical oscillations of electrode-carriers and electrodes decreasing, if voltage in arcs is increased. The analysis of the characteristics represented in fig. 2 allows one to draw a conclusion: electromechanical processes in EAF are defined not only by gradients of potential in arc discharges, as it was believed until nowadays, but also by the electromagnetic processes of interconnection of phases. Arc discharges ensure the functions of transforming electrical energy into thermal and acoustic and act as a source of primary disturbances occurring in the circuit, which are amplified in the system of energy transfer between current leads of short circuit. 


\section{ENERGETIC MODES OF FUNCTIONING OF EAF WITH SHORT AND LONG ARCS}

Change of dynamic components in three-phase electrical circuit of EAF results in rearrangement of integral power generated by arc discharges. Fig. 3 shows the electric characteristics of each of the investigated phases A, B, C and the sums of powers of the three phases under various lengths of arc discharges in phases $\mathrm{A}$ and $\mathrm{B}$ and variations of current in phase $\mathrm{C}$.

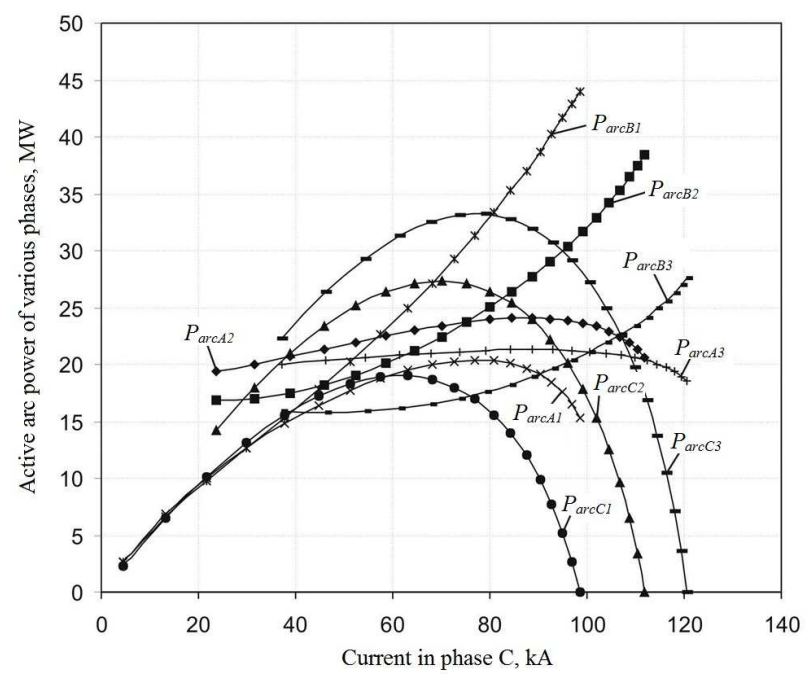

a)

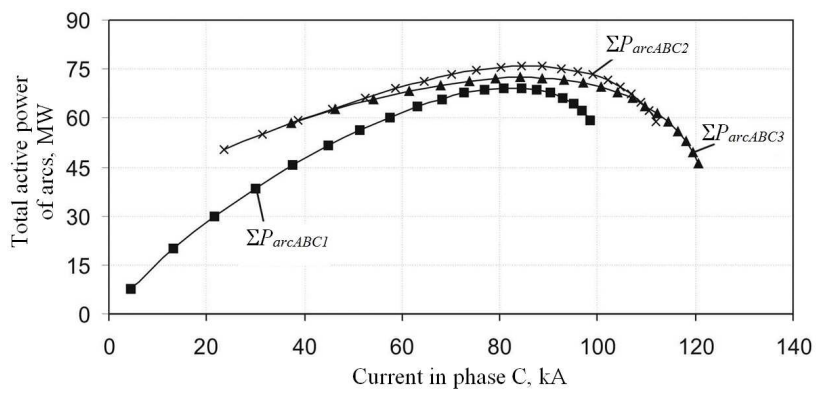

b)

Fig. 3. Active power of phases (a) and total power (b) under various legths of phase arc discharges depending on the phase current

Dependences of power in phase $\mathrm{C}$ on the variation of current in this phase under the conditions of electromagnetic interaction with phases $\mathrm{A}$ and $\mathrm{B}$ show that with long arcs in phases $\mathrm{A}$ and $\mathrm{B}$, under the influence of neighbouring phases, power of the arc in phase $\mathrm{C}$ turns out to be almost 2 times lower in maximum than with short arcs, i e $\mathrm{P}_{\operatorname{arcC} 3}>>\mathrm{P}_{\operatorname{arcCl} 1}$. The effect of restriction of the introduced power due to electromagnetic interaction of phases is exhibited.

In case of alteration of current in phase $\mathrm{C}$ with phases $\mathrm{A}$ and $\mathrm{B}$ under long arc mode, a substantial increase in arc power occurs in phase $\mathrm{B}$, due to the increase of resulting current to the point of values matching those of the current of a short circuit. With short arcs in phases A and B the influence of current alterations in phase $\mathrm{C}$ on the arc power in phase $\mathrm{B}$ matches in quality, but turns out to be significantly less in absolute value $\mathrm{P}_{\mathrm{arcB} 3}<\mathrm{P}_{\text {arcB1}}$. Therefore, under long arc modes the probability of false short circuits is high.

In phase $\mathrm{A}$ under the long arc mode, if the current in phase $\mathrm{C}$ is raised until $60 \mathrm{kA}$, the active power proves to be equal to the power of phase $\mathrm{c}$, and further increasing of current results in increase in arc power, i. e. $\mathrm{P}_{\operatorname{arcAl} 1}>\mathrm{P}_{\mathrm{arcCl}}$. Under short arcs in phases $\mathrm{A}$ and $\mathrm{B}$, the active power in phase A only changes slightly and doesn't go beyond $\mathrm{P}_{\mathrm{arcC} 3}$ in the whole range of current variations in phase $C$. The results of the investigations show substantial differences in the variation dynamic of energetic interactions in the three-phase circuit of the EAF in case of alterating the resistances of arc discharges by changing their length. In fact, the system of automatic control over vertical movements of electrodes in EAF compensates the changes of introduced energy occurring due to transfer of energy between phases

One has to note that the results of investigations of long and short electric arc modes in the electrical furnace EAF-100 are valid for a current lead with asymmetrical active resistances: $X_{A}=X_{C} \neq X_{B}$. This variant of construction of furnace has been chosen deliberately for numerical investigation of functioning of an electrical furnace, since in this case the determined connections between phases are more apparent. The conducted numerical investigations of the modes of the same electrical furnace with triangulated current lead with asymmetry in phases lower than $5 \%$ have exhibited results which only differ in quantity in the range of $\pm 10 \%$ in active and reactive energies. In terms of quality, the variations of furnace parameters match the parameters of EAF-100 with coplanar current lead.

The most informative characteristics for evaluating the difference between the functioning of long and short electric arc modes in EAF are those of the sum of powers of electric arcs of three phases, presented on the fig. 3 .

In the examined calculation example, the total power of three arc discharges in long arc mode $\mathrm{P}_{\mathrm{ABC} 1}$ proves to be lower by $8-17 \%$ than the power achieved by running the furnace under short and medium arcs, and therefore lower voltages at arc intervals in three-phase circuit of EAF. In order to analyze the results, let us find the average value of reactances of the phases:

$\left.\mathrm{X}_{\mathrm{av}}=\left(\mathrm{X}_{\mathrm{A}}+\mathrm{X}_{\mathrm{C}}+\mathrm{X}_{\mathrm{B}}\right) / 3=4.6808+4.3976+4.6808\right) / 3=4.5864 \mathrm{~m} \Omega$.

Reactance of the arc interval $X_{\text {arc }}$ in the examined preliminary analysis can be ignored as it does not exceed $3 \%$ from $X_{a v}$. Active resistance of phases is made up of the resistance of arc $R_{\text {arc }}=\mathrm{U}_{\mathrm{arc}} / \mathrm{I}_{\text {arc }}$ and resistance of current lead $\mathrm{R}_{\mathrm{cl}}=\mathrm{R}_{\mathrm{A}}=\mathrm{R}_{\mathrm{B}}=\mathrm{R}_{\mathrm{C}}=0.45 \mathrm{~m} \Omega$, i.e. $\mathrm{R}_{\mathrm{\Sigma}}=\mathrm{R}_{\mathrm{arc}}+\mathrm{R}_{\mathrm{cl}}$. For a long arc, $\mathrm{R}_{\Sigma 1}=400 / 83000+0.45 \cdot 10^{-3}=5.27 \mathrm{~m} \Omega$, for a medium arc, $\mathrm{R}_{\Sigma 2}=400 / 84000+0.45 \cdot 10^{-3}=4.02 \mathrm{~m} \Omega$, for a short arc, $\mathrm{R}_{\Sigma 2}=400 / 86000+0.45 \cdot 10^{-3}=2.775 \mathrm{~m} \Omega$.

Comparison of the determined values of resistances shows that if active resistance of phase $\mathrm{R}_{\Sigma}$ exceeds average reactive resistance of phase $X_{a v}$, it results in restriction of active power introduced into the furnace which occurs due to 
electromagnetic energy transfer between phases. Under long arcs, $\mathrm{R}_{\Sigma 1}=5.27 \mathrm{~m} \Omega$ is higher than $\mathrm{X}_{\mathrm{av}}=4.5864 \mathrm{~m} \Omega$ by $15 \%$, which leads to a decrease in total active power of the furnace in the whole range of current variation in phase C. Such restriction of active energy introduced into the furnace is not observed with medium and short arcs, as $\mathrm{R}_{\Sigma 2}<\mathrm{X}_{\mathrm{av}}$ and $\mathrm{R}_{\Sigma 3}<\mathrm{X}_{\mathrm{av}}$ operation under long arcs requires an increase of reactance of phases.

Thus one may consider one of the stages of the algorithm of phase reactance control in case of adding real-time operated reactors into the circuit on the primary side of the furnace transformer to be established and confirmed. The realization of inequation $\mathrm{R}_{\Sigma} \leq \mathrm{X}_{\mathrm{av}}$ must be ensured.

\section{SUMMARY}

In the examined mathematical experiment, the outcome values of parameters of averaged phase resistances can be considered valid only for a generalized analysis of the functioning of EAF, as in a real EAF, the change of modes in three phases in the range of maximums of arc power and active power of the furnace occurs simultaneously. Nevertheless, a conclusion can be drawn that for the employment of long arc modes, an additional introduction of reactance with reactors controlled per phase is needed.

\section{References}

[1] V.S. Cherednichenko, R.A. Bikeev, "Electromagnetic processes in the laboratory of superpower electric arc furnaces", Russian Metallurgy, vol. 12, pp. 945-950, 2014.

[2] V.S. Cherednichenko, R.A. Bikeev, "Simulation of electromagnetic processes in three-phase electric arc furnaces", Russian Electrical Engineering, vol. 8, pp. 464-470, 2015.

[3] V.S. Cherednichenko, R.A. Bikeev, A.V. Cherednichenko, A.M. Ognev, "Acoustic characteristics of electric arc furnaces", Russian Metallurgy, vol. 6, pp. 509-516, 2016.

[4] A. Sawicki, "Modele łuku elektrycznego o sterowanej długości", Wiadomości Elektrotechniczne, vol. 7, pp. 15-19, 2012.

[5] A. Sawicki, "Zmodyfikowane modele Habedanka i hybrydowy TWV łuku o zmiennej długości do symulowania procesów w urządzeniach elektrycznych", Biuletyn Instytutu Spawalnictwa, vol. 1, pp. 45-49, 2012.

[6] A. Sawicki, "Modelowanie łuku elektrycznego o zaburzanej długości kolumny plazmowej”, Śląskie Wiadomości Elektryczne, vol. 1, pp. 9-17, 2012.

[7] A. Sawicki, "Modyfikacje modelu Woronina kolumny łukowej o sterowanej długości do symulowania procesów w silnoprądowych urządzeniach elektrycznych”, Śląskie Wiadomości Elektryczne, vol. 1, pp. 18-23, 2012

[8] A. Sawicki, "O wykorzystaniu modelu Woronina kolumny łukowej do symulowania procesów w aparatach i urządzeniach elektrycznych", Przegląd Elektrotechniczny, vol. 1a, pp. 196-200, 2012.

[9] A. Sawicki, "O wykorzystaniu zmodyfikowanych modeli Cassiego do symulowania wpływu zaburzeń długości kolumny łukowej na pracę urządzeń elektrycznych", Przegląd Elektrotechniczny, vol. 9a, pp. 107$110,2012$.

[10] A. Sawicki, "Modelowanie łuku elektrycznego o zmiennych rozmiarach geometrycznych", Zeszyty Naukowe Politechniki Łódzkiej, Łódź Elektryka, vol. 124, pp. 202-214, 2012.

[11] A. Sawicki, "Funkcje wagowe w modelach hybrydowych łuku elektrycznego", Śląskie Wiadomości Elektryczne, vol. 5, pp. 15-19, 2012.
[12] A. Sawicki, "Problems of modeling an electrical arc with variable geometric dimensions", Przegląd Elektrotechniczny, vol. 2b, pp. 270$275,2013$.

[13] A. Sawicki, "Assessement of power parameters of asymmetric arcs by means of the Cassie and Mayr models", Przegląd Elektrotechniczny, vol. 2, pp. 131-134, 2011.

[14] R.A. Bikeev, V.S. Cherednichenko, M.G. Kuz'min, "Metal Losses and the Heat-and-Mass Transfer in the Working Space of Superpower Arc Steelmaking Furnaces", Russian metallurgy, vol. 6, pp. 466-470, 2014.

[15] A.M. Krouchinin, A. Sawicki, A theory of electrical arc heating. Częstochowa: The Publishing Office of Technical University of Częstochowa, 2003.

[16] C. Mapelli, S. Baragiola, "Evaluation of energy and exergy performacnes in EAF during melting and refining period", Ironmaking and Steelmaking, vol. 5, pp. 379-388, 2006. 